\title{
Building and Publishing Fundamental Transit Data for Regional Public Transportation Provided by Municipalities
}

\author{
Chinasa Sueyoshi ${ }^{1, a}$, Hideya Takagi ${ }^{2}$, Yoshihiro Yasutake ${ }^{1}$ and Kentaro Inenaga ${ }^{1}$ \\ ${ }^{1}$ Faculty of Science and Engineering, Kyushu Sangyo University, 2-3-1 Matuskadai, Higashi-ku, Fukuoka city, Fukuoka, Japan \\ ${ }^{2}$ Graduate School of Information Science, Kyushu Sangyo University, 2-3-1 Matuskadai, Higashi-ku, Fukuoka city, Fukuoka, Japan
}

\begin{abstract}
Public transportation is becoming increasingly important in regions where the residential population is decreasing. In Japan, many regional transportation systems are experiencing financial challenges. It is difficult for fixed-route transportation systems to operate at a surplus when serving only local resident users. We consider one of the problems of these regional public transport systems to be the lack of information on the Internet about regional public transportation routes. For people who are unfamiliar with the region, such as inbound tourists, there is no easy way to conduct a route search. In this paper, we describe our efforts to build a fundamental database of the regional public transportation provided by municipalities and to publish this data for those conducting route searches on the Internet. Specifically, we converted fundamental data regarding regional public transportation to the feed of the General Transit Feed Specification-Japan (GTFS-JP), which is based on the Google GTFS, as formulated by the Ministry of Land in Japan. Then we encouraged municipalities to publish these transit data to enable route searches on Google Maps and other domestic-content providers.
\end{abstract}

\section{Introduction}

Domestic regional transportation is positioned as one of the foundations of regional revitalization in Japan. However, contrary to its importance, public transport has not been promoted. According to the Japan Bus Association, the number of passenger buses in Japan has declined, peaking at about 10.1 billion in 1968 and 4.3 billion in 2015 [1]. Although municipalities have made various efforts to address the lack of regional public transportation services that have arisen due to the abolition of private fixed-route transportation, most municipalities manage "community bus" services to improve the welfare of their residents [2]. It's filled the gaps in transport services in less accessible areas, and to promote the outdoor activities of elderly people and the general use of public facilities. Managing regional public transportation efficiently is an ongoing challenge due to the lack of human resources and the current financial constraints on regional public transportation in Japan [3]. Most municipalities have no specialized division of public transportation. As such, it is difficult for fixedroute transportation services to operate at a surplus when serving only local resident users.

One of the problems in regional public transportation is that there is no fundamental transportation data available for making route searches on the Internet. For people who are unfamiliar with a region, such as inbound tourists, the lack of route search capability for regional transportation means that no transportation service is available. Figure 1 shows part of the results of a publicopinion survey on public transport [4] by the Cabinet Office (Government of Japan). The data show that route search services are most often used for public transport checks, route type, high-speed bus, short-to-long-distance railway, etc. For such reports, immediate response by the route-search service regarding regional public transport is desired. We think it is necessary people who do not know the region, it means that transportation does not exist if no regional transportation is found by such a service on the Internet. Solving this problem could revitalize not only regional public transportation services but the region itself.

In this study, we converted fundamental data on regional public transportation to the feed of the (General Transit Feed Specification-Japan (GTFS-JP), which is based on Google's GTFS and was formulated by the Ministry of Land in Japan [5]. The GTFS defines a common format for public transportation schedules and associated geographic information [6]. Figure 2 shows the GTFS/GTFS-JP flow from public facilities to Google and other domestic-content providers. There are municipalities that are managed by paper style such as time schedules so that digitizing the basic data enables easy route search and is expected to be used for the analysis of various operation statuses. This digitalization is a symbol of the promotion in ICT that has tackled regional public transportation in Japan, and it is closely related to the future of transportation such as MaaS

a Corresponding author: sueyoshi@is.kyusan-u.ac.jp 


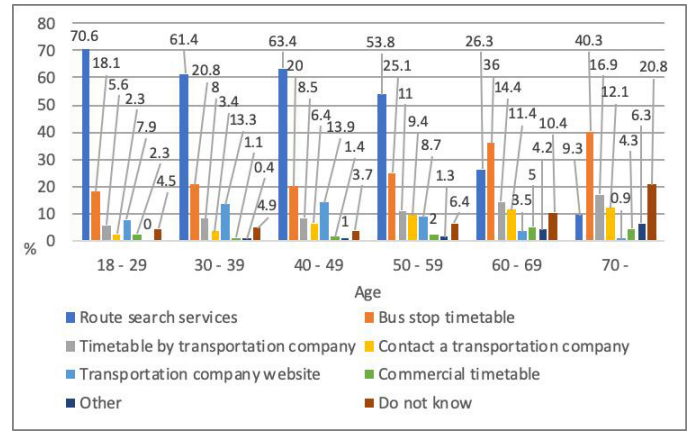

Figure 1. How to check usage method / route in the case of route bus (priority graph created in source data [4])

(Mobility as a Service), which is one of the latest trending important keywords related to transportation.

\section{Building and Publishing Fundamental Data}

Table 1 shows a list of GTFS configuration files. The difficulty and a large amount of work required to describe these specialized areas of knowledge are obstacles to the creation of a GTFS, which requires a range of ICT support addresses.

Table 1. GTFS configuration files.

\begin{tabular}{|c|c|}
\hline File name & Definition (Description) \\
\hline agency.txt & $\begin{array}{c}\text { One or more transportation } \\
\text { agencies that provide data }\end{array}$ \\
\hline stops.txt & Boarding point \\
\hline routes.txt & Transportation route \\
\hline trips.txt & Itinerary for each route \\
\hline stop_times.txt & $\begin{array}{c}\text { Arrival and departure times at } \\
\text { each stop for each itinerary }\end{array}$ \\
\hline fare_attributes.txt & Route fee information \\
\hline shapes.txt & Rules for drawing a route line \\
\hline
\end{tabular}

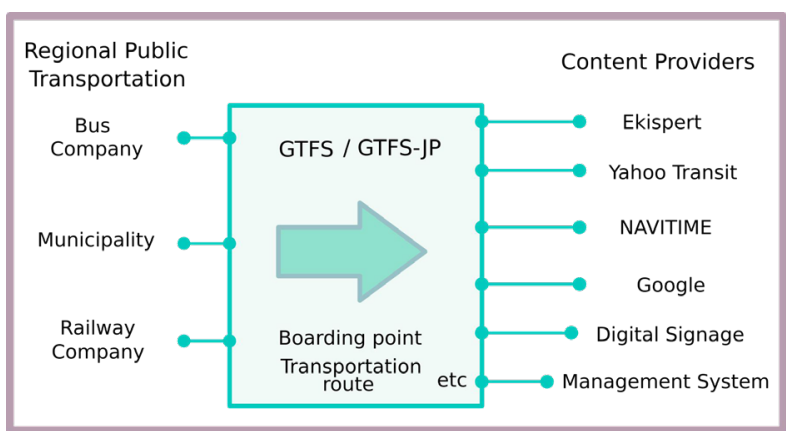

Figure 2. GTFS/GTFS-JP flow from public facilities to Google and other domestic-content providers

The Ministry of Land, Infrastructure, Transport and Tourism, the Kyushu District Transport Bureau Traffic Planning Division, and the Fukuoka Prefecture Transportation Division, Information Policy Division have promoted the building and publishing of GTFS-JP feeds containing transit-site data on the Internet and the providing these feeds to Google and domestic-content providers, such as Ekispert [7], Yahoo Transit [8] and NAVITIME [9]. One example of the use of GTFS for domestic regional public transportation is OpenTrans.it [10] built by Masaki Ito and others at the University of Tokyo for public transportation data feed in Shimada City and Yaizu City, Shizuoka Prefecture. We think that information regional public transportation to content providers will be more promoted than ever if it has been building about on fundamental GTFS/GTFS-JP as shown in Figure 2. As a result, regional public transportation and content providers can be easy to share data for route searches, so that it contributes to improving convenience for regional public transportation users.

Our laboratory team developed a practical solution for regional public transportation services provided by the service management support systems of municipalities in

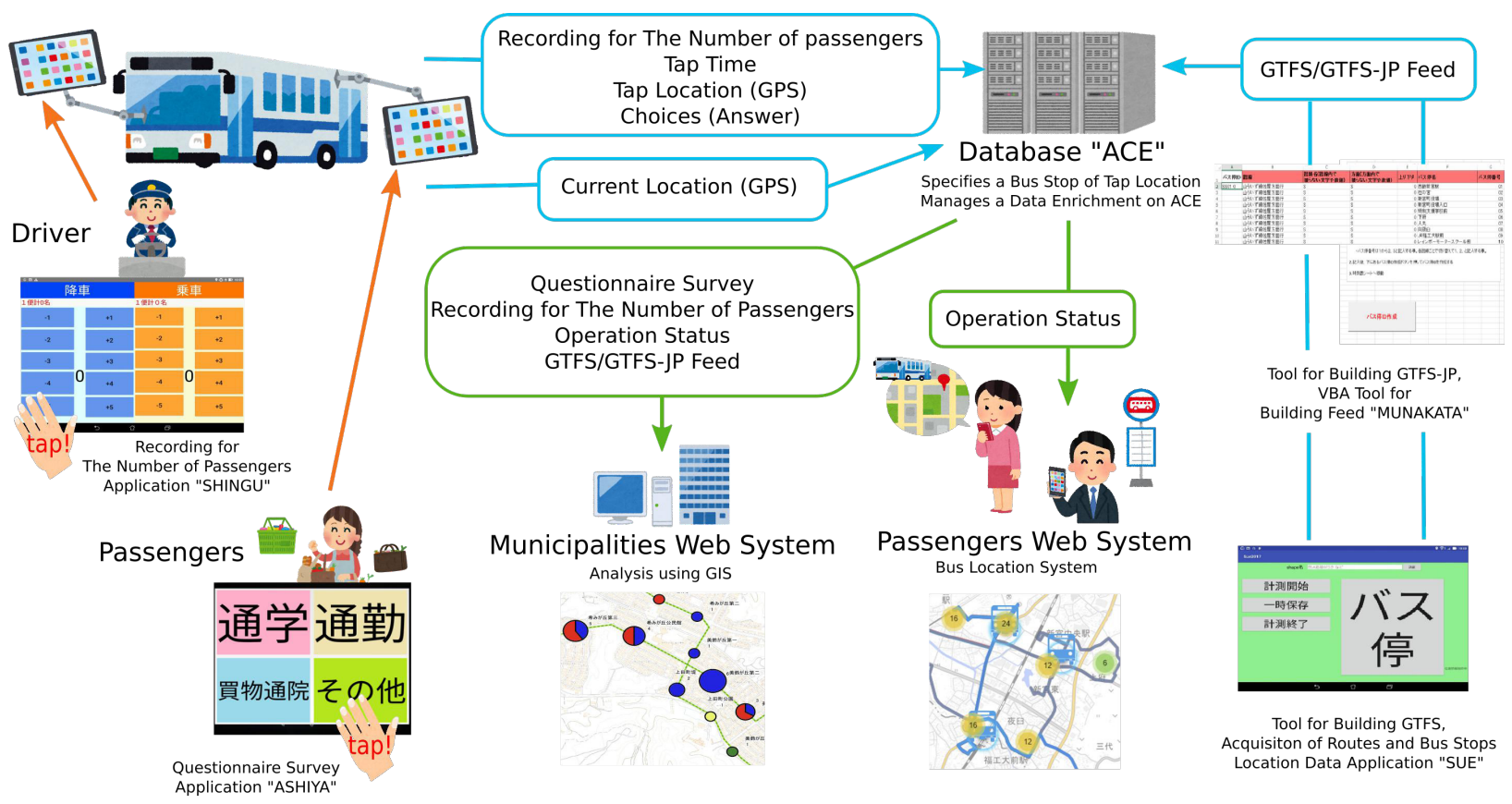

Figure 3. Support system for public transportation management using the applications SHINGU and ASHIYA 


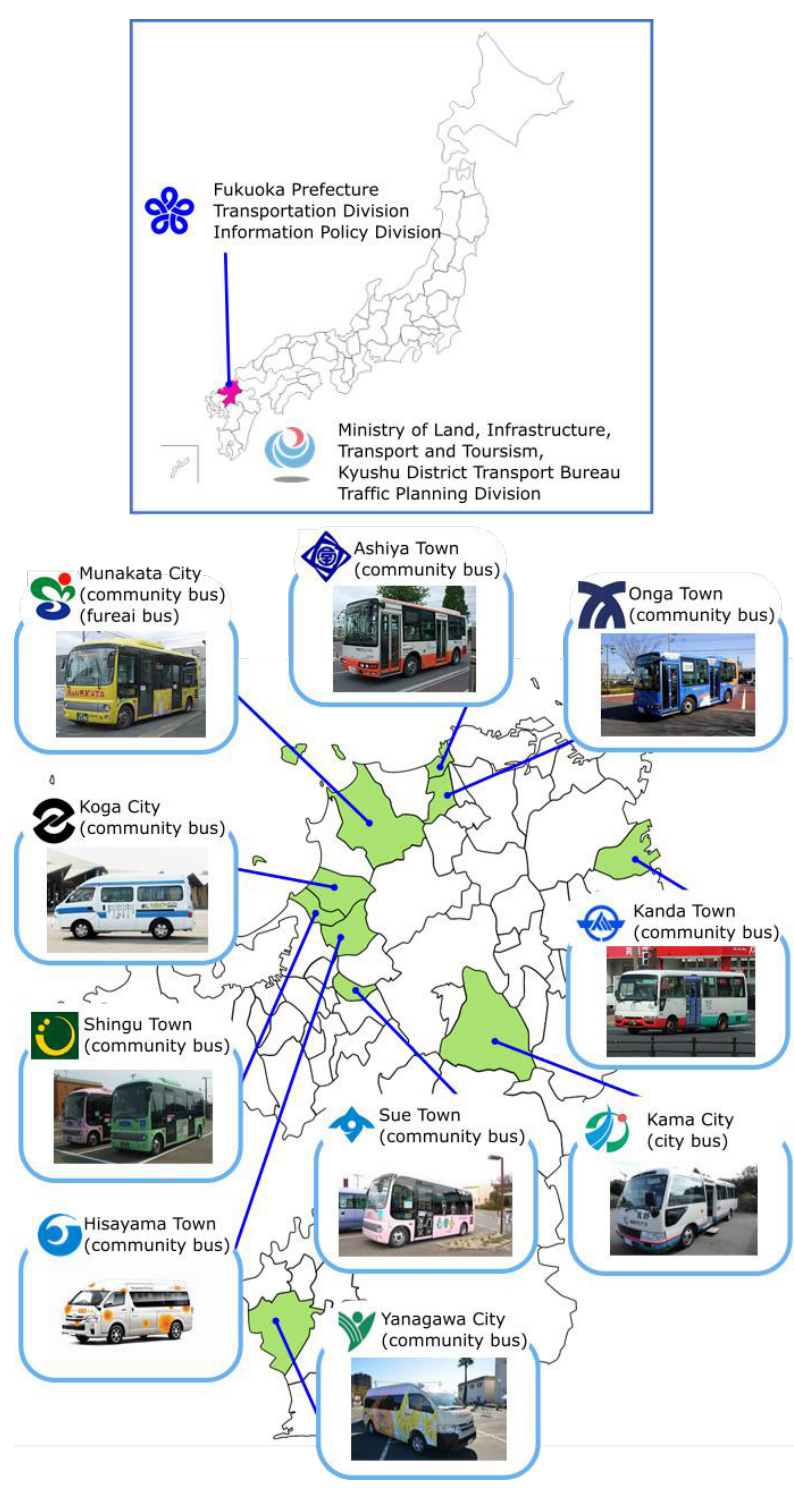

Figure 4. The fundamental data of regional public transportation to the feed of GTFS-JP in cooperation with community bus and local government organ.

Japan $[11,12]$. Figure 3 shows a schematic outline of the system. First, all data is managed by ACE that has GTFS, GTFS-JP, the number of bus passengers and analysis results. We assign two tablets to each bus, one of which uses the application SHINGU to record the number of bus passengers and the second provides a questionnaire survey for passengers using the application ASHIYA. Using SHINGU, the bus driver records the passengers who get-on/get-off the community bus by simply tapping. Passengers use ASHIYA by tapping to answer the questionnaire on each community bus. The obtained data includes the number of passengers, the tap time, the tap location by GPS, the answers provided on the questionnaire by passengers and the current GPS location of the bus. These data are sent to the ACE database. We also developed a tool for building the GTFS, the application SUE used to acquire routes and bus-stop location data, and a VBA tool for building the GTFS-JP and feeding the data to the city of Munakata. The data

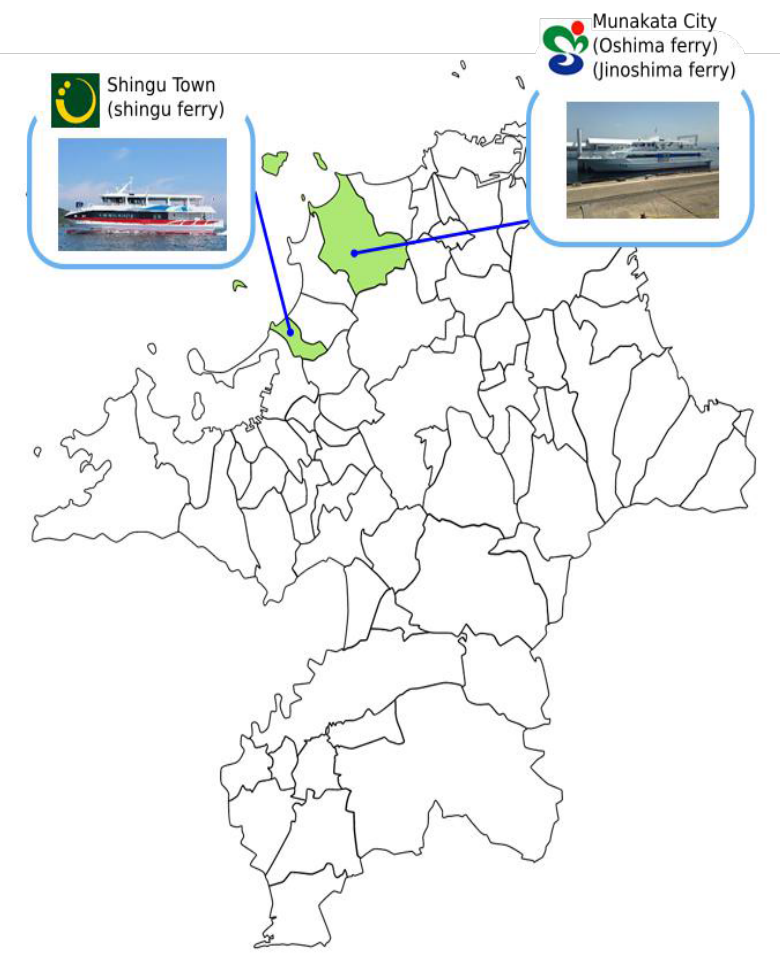

Figure 5. The fundamental data of regional public transportation to the feed of GTFS-JP in cooperation with the ferry.

generated by these tools are stored in the ACE database, which maintains raw tap data and performs data enrichment. In this study, we analyzed the GIS data and some data from the questionnaire surveys, including the number of passengers, the operational states, and the GTFS/GTFS-JP feed. The results enable us to visualize a bus stop with many passengers. Moreover, the bus location system uses the operation status available in ACE. This bus location system is a convenient tool for bus passengers because it contains information such as how many buses have passed through a bus stop.

Tablets equipped with the Android application SHINGU are used by tablets with mobile data communication in our system to record the number of passengers and collect passenger data as a concrete means of utilizing ICT to conduct a long-term and continuous survey of transportation service usage. Previous studies have used SHINGU ver.2 in Android applications and SHINGU mini on smartphones. In this study, we integrated these two systems. SHINGU ver.3 is configured in four modes, which provide transitions for inputting the number of get-off/get-on passengers, transitions for displaying the setup and backup databases, deleting the backup database, and synchronous communication. SHINGU mini is configured in five modes, i.e., inputting the number of get-off passengers or get-on passengers, making transitions on inputting the number of get-off or get-on passengers, making transitions in the display of the setup and backup databases and deleting backup databases. The SHINGU mini separates the input of the number of get-off /get-on passengers. 


\section{Cooperation with community bus and local government organ}

As shown in Figures 4 and 5, we built a fundamental database of regional public transportation for the GTFSJP feeds in cooperation with multiple municipalities. Figure 4 shows practical examples of bus services and Figure 5 shows those for ferry services. First, we built the GTFS feed for the bus service in Shingu Town in 2016 [13] and that in Munakata City in 2017. Since 2017, we have built GTFS-JP feeds for the bus services in 10 municipalities as well as for the ferry services in the city of Munakata and the town of Shingu. Building and publishing the GTFS-JP feed for the bus and ferry services in Shingu has increased bus usage by about $60.0 \%$ by people from outside the area who were unfamiliar with the region, such as inbound tourists [14]. The town of Shingu has a tourist destination, Ainoshima Island, i.e., "cat island."

For further study, it will be necessary to cooperate with local companies to promote regional development and with the Kyushu District Transport Bureau and Fukuoka Prefecture to support the building and publishing of fundamental transit data. Furthermore, to promote future transit development and verify current services, it is necessary for the companies providing transportation services to have access to the data.

\section{Conclusion}

The conversion of data by local governments, as the main operators of local public transport services, into the required data format for Internet route searches is not practical either in terms of technology or cost. Currently, this service is not supported. Efficient regional public transportation management in Japan is challenging due to the constraints on human resources and finances. In this paper, we describe our efforts to build and publish GTFSJP feeds for multiple municipalities based on fundamental data to make public transportation services available in route search results by Google and other domestic-content providers.

\section{Acknowledgment}

The authors would like to thank Shingu Town Kasuya County, Munakata City, Sue Town Kasuya Country, Ashiya Town Onga Country, Koga City, Onga Town Onga Country, Kama City, Kanda Town Miyako Country, Ogori City, Yanagawa City, Fukuoka Prefecture. And the Advanced ICT Human Resource Education University Consortium on the theme of solving regional issues, Fukuoka Prefecture Planning and Regional Promotion Department Transportation Policy Division, Information Policy Division and the Transportation Planning Division, Kyushu Transportation Bureau, Ministry of Land, Infrastructure, Transport and Tourism for their opportunities to us collaborative research and study. This work was supported by JSPS KAKENHI Grant Number JP17K00472.

\section{References}

1. Nihon Bus Association, "Overview of Japan bus business and Nihon Bus Association 2017," Sep. 2019.[Online].Available:http://www.bus.or.jp/about/ pdf/h29_nba_brochure.pdf.

2. Ministry of Land, Infrastructure, Transport and Tourism:Concept and type of community bus. Accesses:Sep.2019.[Online].Available:http://www.m lit.go.jp/singikai/koutusin/rikujou/jidosha/bus/01/ima ges/06.pdf.

3. Ministry of Land, Infrastructure, Transport and Tourism:Current status of regional public transportation in Japan. Accesses : Sep. 2019.[Online].Available:http://wwwtb.mlit.go.jp/kin ki/content/000010186.pdf.

4. Cabinet Office, "Public opinion survey on public transportation,’Sep.2019.[Online].Available:https://s urvey.gov-online.g.,o.jp/h28/h28-kotsu/2-2.html.

5. Ministry of Land, Infrastructure, Transport and Tourism : GTFS-JP. Accesses : Sep. 2019.[Online]. Available:http://www.mlit.go.jp/common/001283244. pdf.

6. Google, GTFS Static Overview. Accesses : Sep. 2019.[Online].Available:https://developers.google.co $\mathrm{m} /$ transit/gtfs/.

7. Ekispert, Ekispert for WEB. Accesses : Sep. 2019. [Online]. Available : https://roote.ekispert.net/ja/.

8. Yahoo Japan, Yahoo Transit. Accesses : Sep. 2019.[Online]. Available : https://transit.yahoo.co.jp/.

9. NAVITIME JAPAN, NAVITIME. Accesses : Sep. 2019.[Online].Available:https://www.navitime.co.jp/.

10. M. Ito and K. Sezaki, "Current status and prospects of public transport open data in Japan," The 55th Infrastructure Planning and Management Research Presentation and Lectures, 2017, 04-01, Committee of Infrastructure Planning and Management.

11. H. Takagi, C. Sueyoshi and K. Inenaga," Developing and Introducing Vehicle Location System for Regional Public Transportation Service Provided by Municipalities Using Fundamental Transit Data," 14th Japanese Conference On Mobility Management, Kanazawa, Ishikawa, Japan, July 2019.

12. K. Inenaga, H. Takagi and C. Sueyoshi," Practical Use of Management Support System and Supporting to Build Fundamental Transit Data for Regional Public Transportation Service Provided by Municipalities in the Kyushu Region" 14th Japanese Conference On Mobility Management, Kanazawa, Ishikawa, Japan, July 2019.

13. K. Inenaga, J. Nishiyama and K. Harada, "The Development of Tools to Provide Fundamental Data Set of Regional Public Transportation," The 15th ITS Symposium 2017 Proceedings, 2017.

14. K. Inenaga, "A Study on the Effectiveness of Introduction to Open-Data for Regional Public Transportation," Proceedings of the 59th National Convention of JAMS, Japan Association for Management Systems, pp.38--41, 2017. 